\title{
Removal of Methyl Violet Dyes from Aqueous Solution using Almond (Prunus dulcis) Seed Shell
}

\author{
Conrad k. Enenebeaku ${ }^{1}$, Nnaemeka J. Okorocha ${ }^{1}$, Emmanuel Nzediegwu ${ }^{1}$, \\ Uchechi E. Enenebeaku ${ }^{2}$ \\ ${ }^{\prime}$ (Department of Chemistry, Federal University of Technology, PMB 1526, Owerri, Nigeria) \\ ${ }^{2}$ (Department of Biotechnology, Federal University of Technology Owerri, Nigeria)
}

\begin{abstract}
The potential of almond seed shell (ASSP), for the removal of methyl violet (MV) dye from aqueous solution was investigated. The adsorbent was characterized by SEM and FTIR analysis. Batch adsorption studies were conducted and various parameters such as contact time, adsorbent dosage, initial dye concentration, $p H$ and temperature were studied to observe their effects in the dye adsorption process. The optimum conditions for the adsorption of MV onto the adsorbent (ASSP) was found to be: contact time (80 mins), $\mathrm{pH}(10.0)$ and temperature $(303 \mathrm{~K})$ for an initial $\mathrm{MV}$ dye concentration of $50 \mathrm{mg} / \mathrm{L}$ with adsorbent dose of $1.0 \mathrm{~g}$. The experimental equilibrium adsorption data fitted best and well to the Freundlich isotherm model for the dye adsorption. The maximum adsorption capacity was found to be $628.93 \mathrm{mg} / \mathrm{g}$ for the adsorption of MV dye. The kinetic data conformed to the pseudo-second-order kinetic model. Thermodynamic quantities such as Gibbs free energy $\left(\Delta G^{0}\right)$, enthalpy $\left(\Delta H^{0}\right)$ and entropy $\left(\Delta S^{0}\right)$ were evaluated and the negative values of $\Delta G^{0}$ obtained indicated the spontaneous nature of the adsorption processes. The negative $\Delta H^{0}$ and positive values of $\triangle S^{0}$ indicate the exothermic nature and increased randomness during the adsorption of MV onto ASSP.
\end{abstract}

Keywords: Adsorption, Almond Seed Shell, Methyl Violet (MV) Dye, Isotherm, Kinetics.

\section{Introduction}

A dye is a coloured substance that has affinity to the substrate to which it is being applied. The dye is generally applied in an aqueous solution, and requires a mordant, to improve the fastness of the dye on the fibre. Dyes are of synthetic origin and complex molecular structure which make them more stable and non biodegradable [1]. They are extensively used in paint, leather, paper, plastics, food, cosmetics, textile and pharmaceutical industries etc to colour their products [2,3]. About 100,000 commercial dyes are manufactured including several varieties of acidic, basic, reactive, azo, diazo and anthraquinone based metal complex dyes. Over 10,000 dyes with an annual production of over $7 \times 10^{6}$ metric tons are commercially available [4]. Textile industries are found in most countries and their numbers have increased [5]. The textile industry consume more than $60 \%$ of the dye world production with an annual world production of about 30 million tonnes of textiles requiring about 700,000 tonnes of different dyes [6]. This industry consumes very large volume of Water and chemicals for the wet processing of textiles and the effluents from the industries are usually discharged into water bodies. Dye containing effluents from textile and dyestuff industries are the most difficult to treat and present unique problems as they show resistance to many chemicals, oxidizing agents, light and heat and are biologically non-biodegradable [6]. It is therefore necessary to remove these dyes from the effluents (wastewater) with suitable technology before discharging it into receiving water bodies.Over the past few decades, conventional waste water treatment methods for removing dyes include biological (aerobic and anaerobic), chemical and physiochemical methods such as coagulation and flocculation, solvent extraction, membrane filtration ozonation, ion exchange, electrochemical techniques, fungal decolonization and adsorption [1-3]. The removal of dyes from wastewater or industrial effluent using adsorption method is preferred to other methods of removal of dyes due to its simplicity of design, more efficient, easy to operate, insensitive to toxic substances and cost effective. It therefore provides an alternative method to other expensive existing physical/ chemical/ biological methods for the removal of dyes from industrial effluents or waste water [6]. Adsorbents obtained from plant materials are currently being researched as effective substitutes for conventional adsorbents like activated charcoal; since the plant materials are relatively cheaper, readily more available. In view of this, the present study aims at investigating the removal of Methyl Violet dye from aqueous solution using Almond seed shell powder as a low cost adsorbent.

\section{Materials And Method}

\subsection{Materials}

Almond seed shell powder (ASSP), Methyl violet dye (MV), Hydrochloric acid ( $\mathrm{HCl}$ ) and Sodium Hydroxide $(\mathrm{NaOH})$, Distilled water, Conical flask, and beakers, Measuring cylinders and funnels, Filter paper 
(Whatman NO.1), Digital pH meter, Electrical shaker, Electronic weighing balance, Thermostatic water bath, Ultra-violet visible Spectrophotometer (Model Hitachi - 2800).

\subsection{Adsorbents collection and Preparation}

The Almond seed shell was collected from FUTO and its environs in Owerri west Local Government Area of Imo State, Nigeria. These agricultural wastes (almond seed shell) were properly washed with distilled water to remove sand, dirt and other impurities present in them and dried in an oven $\left(\right.$ at $\left.50{ }^{0} \mathrm{C}\right)$ until all moisture were removed. The dried samples were ground in a mill and sieved in a sieve shaker of particle size $300 \mu \mathrm{m}$. The samples that passed through the sieve were stored in separate air tight containers and used as adsorbent (ASSP) without any further pretreatment.

\subsection{Preparation of adsorbates (MV) Solution}

Stock solution of the dye (Methyl violet) were prepared by dissolving $1 \mathrm{~g}$ of the powdered dye in $1 \mathrm{~L}$ distilled water respectively to have $1000 \mathrm{mg} / \mathrm{L}$ dye concentration in the solutions. Experimental dye solutions of desired concentrations were obtained by appropriate dilution of the stock solution.

\subsection{Adsorbent Characterization}

Fourier transform infra-red (FTIR) spectrophotometer was used to identify the different functional groups available on the adsorbent sites. The FTIR of the adsorbent was taken before and after adsorption of methyl red using FTIR spectrophotometer (Shimadzu-8400S). The adsorbent was encapsulated with $\mathrm{KBr}$ spectroscopy grade and by introducing the mix in a piston's cell of a hydraulic pump with compression pressure $15 \mathrm{KPa} / \mathrm{cm}^{2}$, the solid transluscent disk was obtained. The FTIR spectrum was then recorded within the wave number range $4000-500 \mathrm{~cm}^{-1}$. In addition, surface morphology and texture of the adsorbent was analyzed using scanning electron microscope (SEM) (Model-PHENOM ProX). Prior to scanning, some quantity of the adsorbent was placed on a double adhesive sticker placed in a sputter machine for $5 \mathrm{sec}$; this gave the adsorbent a conductive property. Sample (adsorbent) stud was fixed on a charge reduction sample holder, and then was charged in the SEM machine.

\subsection{Batch Adsorption Experiments \\ 2.5.1 Effect of Contact time}

The Batch adsorption experiment on the effect of contact time on the adsorption of Methyl violet onto almond seed shell powder was performed according to the previous work of Asiagwu et al. [7]. 1g of the adsorbent (ASSP) was weighed into seven different conical flasks. Concentration of $50 \mathrm{mg} / \mathrm{L}$ of the dye was prepared differently from the stock solution by dilution. $100 \mathrm{ml}$ of the $50 \mathrm{mg} / \mathrm{L}$ dye solution was measured into the seven conical flasks. The flasks were labeled for time intervals of 10, 20, 40, 60, 80, 100 and 120 minutes. The flasks were tightly covered and agitated on a rotary shaker $(100 \mathrm{rpm})$ at the appropriate time intervals and at room temperature $\left(27^{\circ} \mathrm{C}\right)$. At the end of each time interval, the flasks were withdrawn and filtered using Whatman No.1 filter paper. The concentration in the supernatant solution was analyzed using UV-visible Spectrophotometer.

\subsubsection{Effect of Adsorbent dose}

The Batch adsorption experiment on the effect of adsorbent dosage on the adsorption of Methyl violet dyes onto almond seed shell powder was performed according to the previous work of Sumanjit et al. [8]. 0.5, 1, 2,3 and $4 \mathrm{~g}$ of the adsorbent (ASSP) were weighed into five different conical flask respectively. 100ml of each dye solution of concentration $50 \mathrm{mg} / \mathrm{L}$ was measured into the five conical flasks. The flasks were then labeled for different dosage of time intervals of $0.5,1,2,3$ and $4 \mathrm{~g}$. The flasks were tightly covered and agitated on a rotary shaker $(100 \mathrm{rpm})$ at contact time of optimum adsorption and at room temperature $\left(27{ }^{0} \mathrm{C}\right)$. At the end of each time interval, the flasks were withdrawn and filtered using Whatman No.1 filter paper. The concentration in the supernatant solution was analyzed using UV-visible Spectrophotometer.

\subsubsection{Effect of Initial MV Concentration}

The Batch adsorption experiment on the effect of initial concentration on the adsorption of Methyl violet dye onto almond seed shell powder was performed according to the previous work of Asiagwu et al. [7]. Several standard Methyl violet dye solutions of 25, 50 75, 100 and $125 \mathrm{mg} / \mathrm{L}$ were prepared from the stock solution. The flasks were then labeled for the different dye concentration of 25, 50 75, 100 and $125 \mathrm{mg} / \mathrm{L} .100 \mathrm{ml}$ of each of the solution was added to accurately weighed $1 \mathrm{~g}$ of the adsorbent into the five different conical flask respectively and agitated at contact time of optimum adsorption and at room temperature $\left(27^{\circ} \mathrm{C}\right)$. At the end of the time intervals, the flasks were withdrawn and filtered using Whatman No.1 filter paper. The concentration in the supernatant solution was analyzed using UV-visible Spectrophotometer. 


\subsubsection{Effect of pH}

The Batch adsorption experiment on the effect of $\mathrm{pH}$ on the adsorption of methyl violet dye onto almond seed shell powder was performed according to the previous work of Kumar et al. [9]. Several $\mathrm{pH}$ of the dye solutions of $2,4,6,8$, and 10 were prepared using $0.1 \mathrm{M}$ of $\mathrm{HCl}$ or $\mathrm{NaOH}$. The flasks were then labeled for the different initial $\mathrm{pH}$ of $2,4,6,8$, and $10.100 \mathrm{ml}$ of each of the solution was added to accurately weighed $1 \mathrm{~g}$ of the adsorbent into the five different conical flask and agitated at contact time of optimum adsorption and at room temperature $\left(27^{0} \mathrm{C}\right)$. At the end of the time intervals, the flasks were withdrawn and filtered using Whatman No.1 filter paper. The concentration in the supernatant solution was analyzed using UV-visible Spectrophotometer.

\subsubsection{Effect of temperature}

The Batch adsorption experiment on the effect of temperature on the adsorption of methyl violet onto almond seed shell powder was performed according to the previous work of Asiagwu et al. [7]. 1g of the adsorbent was weighed into five conical flask and $100 \mathrm{ml}$ of the dye solution of concentration $50 \mathrm{mg} / \mathrm{L}$ was measured into the five conical flasks. The flasks were labeled for temperature of $30,40,50,60$ and $70^{\circ} \mathrm{C}$.The flasks were tightly covered and heated at the appropriate temperature using thermostatic water bath and at contact time of optimum adsorption. At the end of the timing schedule, each of the flasks was brought out and agitated for about five minutes. Then the solutions in the flasks were filtered using Whatman No. 1 filter paper. The final concentrations in the supernatant solution were determined using UV-visible spectrophotometer.

2.6 Dye Uptake

Percentage removal of the dyes was calculated for each sample using:

Dye removal $(\%)=\frac{\mathrm{C}_{\mathbf{0}}-\mathrm{C}_{\mathrm{e}}}{\mathrm{C}_{\mathbf{0}}} \times \mathbf{1 0 0}$

Where $C_{0}$ and $C_{e}$ are initial and equilibrium (final) dye concentrations, respectively.

The amount of dye adsorbed per unit weight of adsorbent at equilibrium $\left(q_{e}\right)$ was calculated as:

$\mathbf{q}_{\mathbf{e}}=\left(\mathbf{C}_{\mathbf{0}}-\mathbf{C}_{\mathbf{e}}\right) \frac{\mathbf{v}}{\mathbf{w}}$

Where $V$ is the volume of experiment solution $(L)$ and $W$ is the mass of adsorbent $(\mathrm{g})$.

\subsection{Adsorbent characterization}

\section{Results And Discussion}

The FTIR spectra of ASSP before and after adsorption (Fig. 1 \& 2) of MV dye were analyzed to determine the vibration frequency changes in their functional groups. For ASSP before adsorption, various

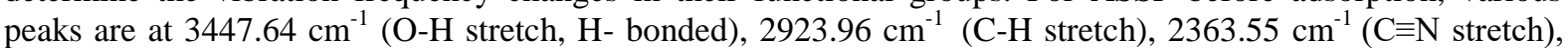
$1734.41 \& 1717.34 \mathrm{~cm}^{-1}(\mathrm{C}=\mathrm{O}$ stretch$), 1647.28 \mathrm{~cm}^{-1}(\mathrm{C}=\mathrm{C}$ stretch $), 1636.50 \mathrm{~cm}^{-1}\left(\mathrm{~N}-\mathrm{H}\right.$ bend from $1^{0}$ amines $)$, $1507.61 \mathrm{~cm}^{-1}$ (C-C stretch in rings), $1489.87 \mathrm{~cm}^{-1}$ (N-O asymmetrical stretch in nitro compounds), $1457.41 \mathrm{~cm}^{-1}$ (C-H bend), $1419.59 \mathrm{~cm}^{-1}\left(\mathrm{CH}_{3}\right), 1244.91 \mathrm{~cm}^{-1}$ (C-N stretch), $1051.43 \mathrm{~cm}^{-1}(\mathrm{C}-\mathrm{O}$ stretch) and $668.62 \& 600.65$ $\mathrm{cm}^{-1}$ (C-Br stretch) [10]. After adsorption of MV dyes it was found out that most of the functional groups on the adsorbent were affected after the dye uptake process. This is judged from shifts in the position of some of the functional groups to lower or higher frequency or band intensity before and after MV adsorption. The functional groups that moved to lower frequency or band intensity after MV adsorption includes: $\mathrm{C} \equiv \mathrm{N}, \mathrm{C}=\mathrm{O}, \mathrm{C}-\mathrm{H}, \mathrm{CH}_{3}$ and $\mathrm{C}-\mathrm{N}$ from $2363.55,1734.41 \& 1717.34 \mathrm{~cm}^{-1}, 1457.41,1419.59$ and $1244.91 \mathrm{~cm}^{-1}$ respectively to 2362.32 , $1697.30 \& 1716.95,1457.31,1418.94$ and $1033.47 \mathrm{~cm}^{-1}$ respectively. The functional groups that moved to higher frequency or band intensity includes: $\mathrm{O}-\mathrm{H}, \mathrm{C}=\mathrm{C}$ and $\mathrm{N}-\mathrm{O}$ from $3447.64,1647.28$, and $1489.87 \mathrm{~cm}^{-1}$ to $3567.29,1670.23$ and $1541.11 \mathrm{~cm}^{-1}$ respectively. This indicates involvement of these groups for MV binding to ASSP [11]. Also, Fig. 3 shows the SEM image of ASSP powder. It can be observed from Fig. 3 that the external surface of ASSP powder is not only rough with irregular ridges but also shows presence of pores.

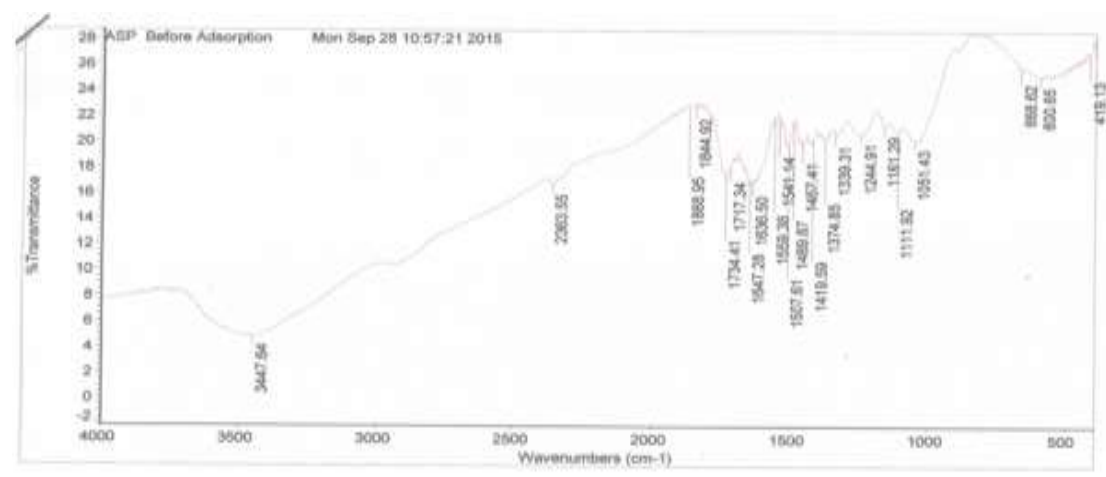

Fig. 1: FTIR Spectra of ASSP before adsorption 


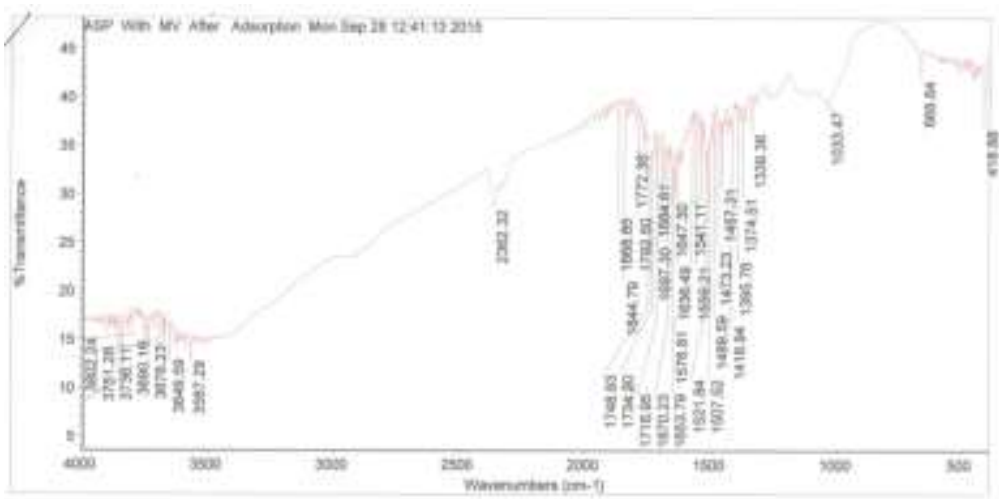

Fig. 2: FTIR Spectra of ASSP after adsorption

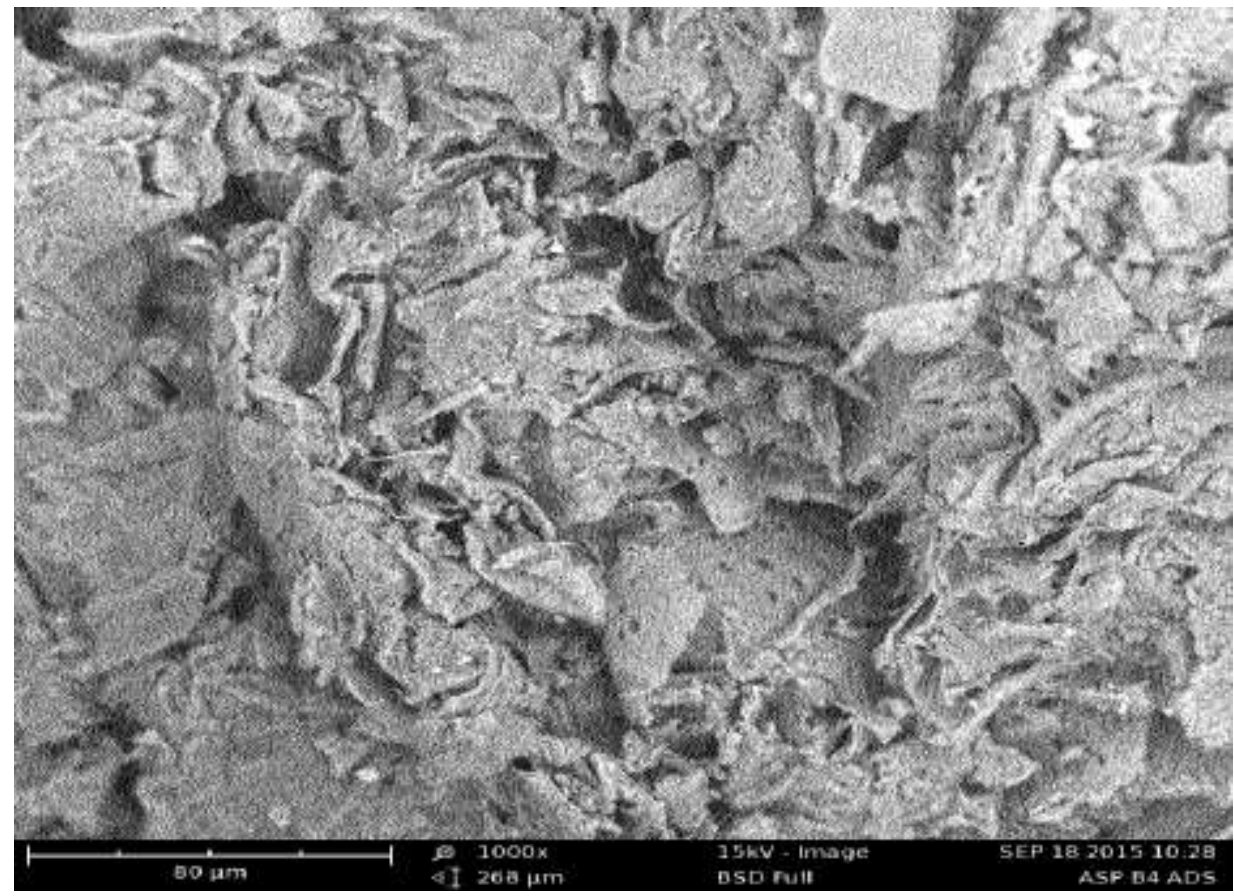

Fig. 3: SEM micrograph of ASSP surface at magnification 1000x

\section{2: Effect of Contact Time}

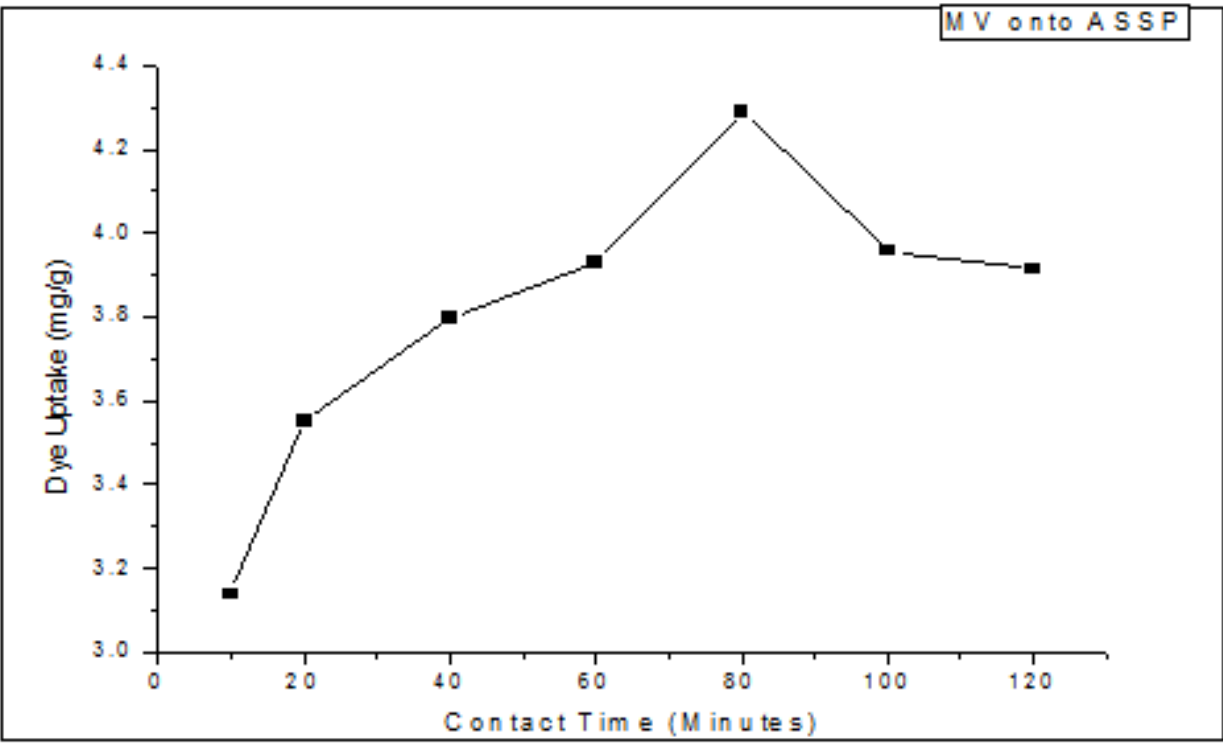

Fig.4: Effect of contact time for the adsorption capacity of MV onto ASSP 


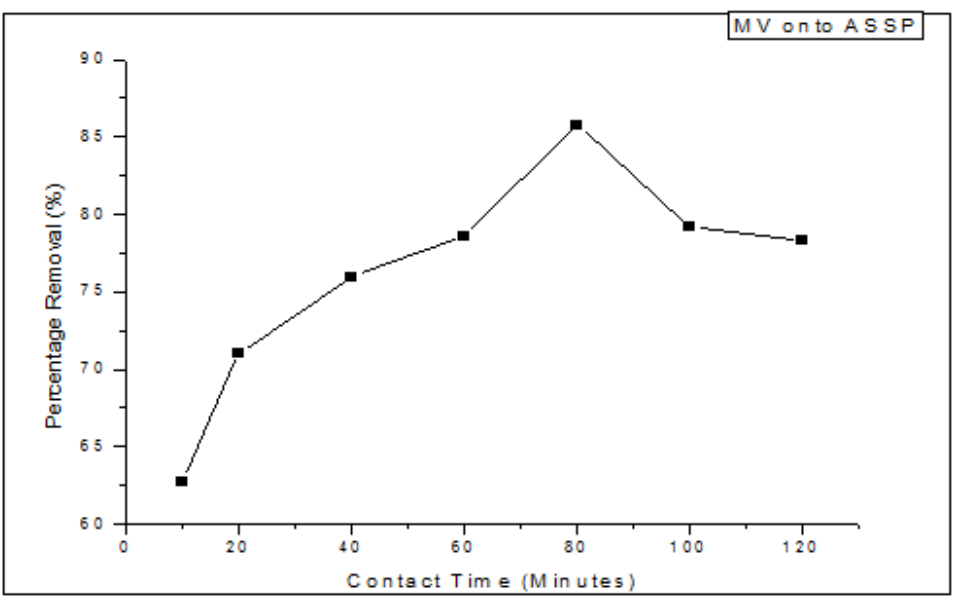

Fig.5: Effect of contact time for the percentage removal of MV onto ASSP

Fig. 4 and 5 show the effect of contact time on the adsorption capacity and percentage removal of MV on to ASSP. It can be observed in Fig.4 and 5 that the sorption of MV dye by ASSP was rapid in the initial stages and becomes slow in later stages until optimum adsorption (equilibrium time) at 80 minutes. It can be inferred from the rapid sorption at the initial stages that there were abundance of active sites on the external surface of ASSP which resulted in the rapid dye removal. The slow rate in the later stages is due to the dyes being diffused into the interior of the adsorbents [12].

\section{3: Effect of Adsorbent Dosage}

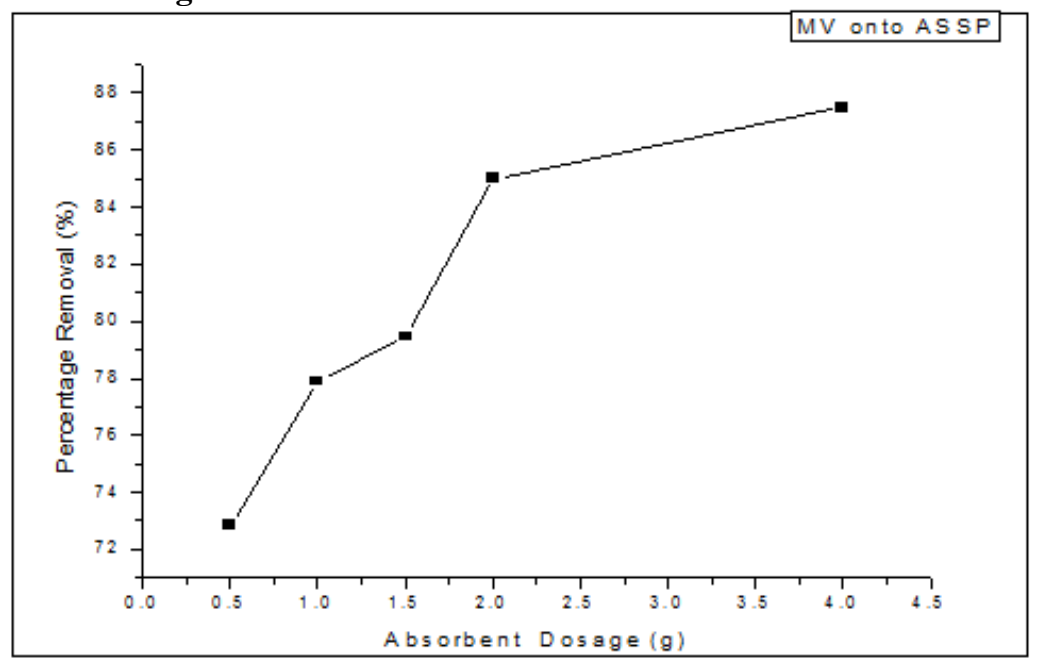

Fig.6: Effect of adsorbent dosage for the percentage removal of MV onto ASSP

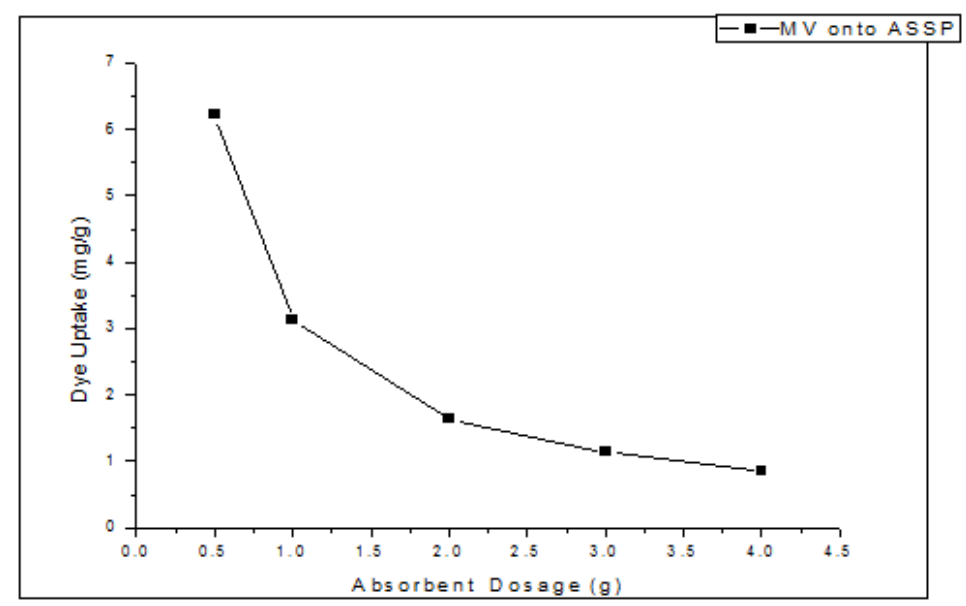

Fig.7: Effect of adsorbent dosage for the adsorption capacity of MV onto ASSP 
Fig. 6 and 7 show the effect of adsorbent dose on the percentage removal and adsorption capacity of MV dye. The percentage removal of MV dye increased from $62.14 \%$ to $68.98 \%$ (Fig.6). While the adsorption capacity of MV dye decreased from $6.21 \mathrm{mg} / \mathrm{g}$ to $0.86 \mathrm{mg} / \mathrm{g}$ respectively (Fig.7) as the dosage increased from 0.5 to $4 \mathrm{~g}$. It is observed that as the adsorbents dosage increased, the amount of dyes adsorbed decrease while the percentage removal of the dyes increased. The decrease in the dye uptake (adsorption capacity) is also due to the splitting effect of flux (concentration gradient) between the adsorbates and the adsorbent [13]. The increase in percentage removal of the dye with increase in adsorbent dose is due to the availability of more adsorption sites with increase in adsorbent dose [14].

\section{4: Effect of Initial Concentration}

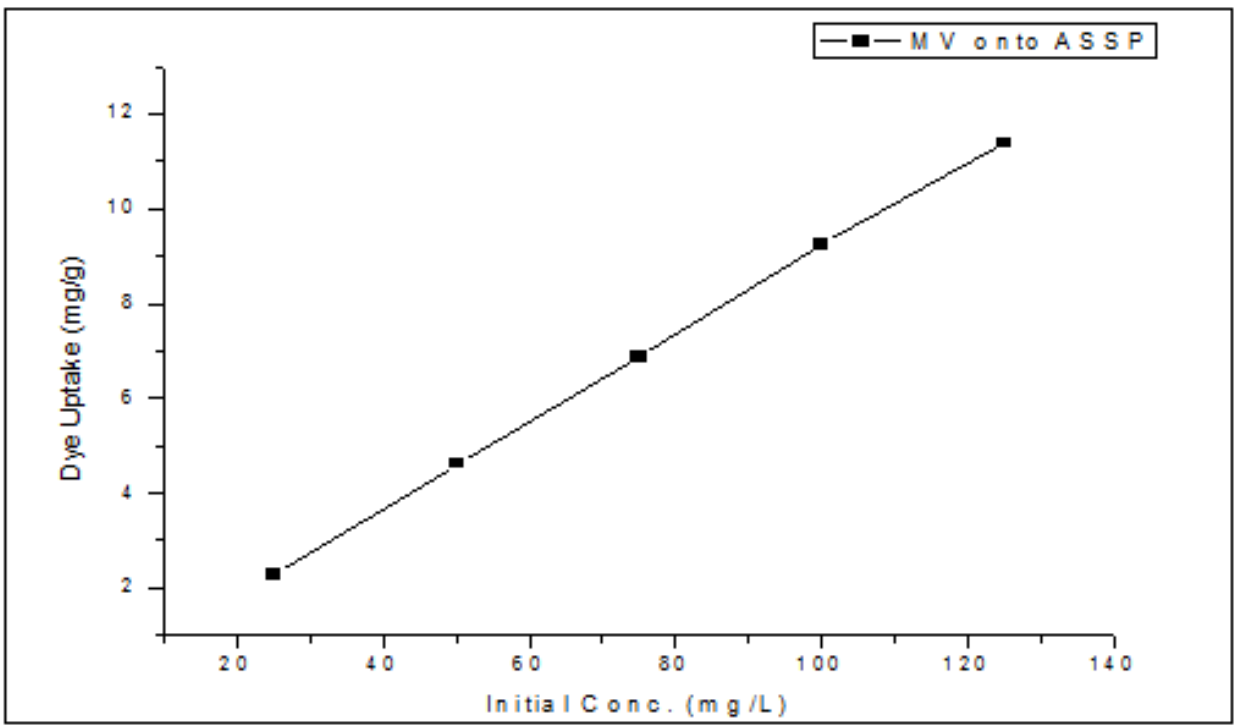

Fig.8: Effect of initial concentration for the adsorption capacity of MV onto ASSP

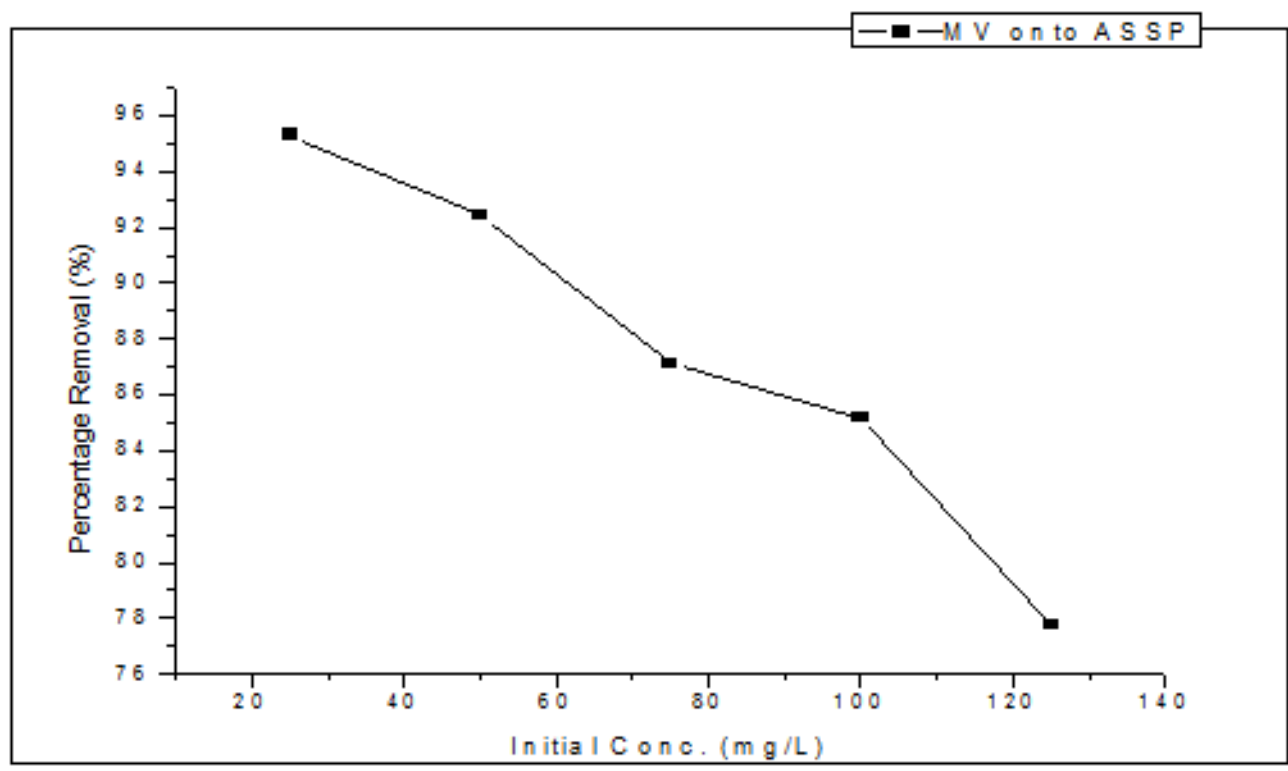

Fig.9: Effect of initial concentration for the percentage removal of MV onto ASSP

Fig. 8 and 9 show the effects of initial concentration on the adsorption capacity and percentage removal of MV dye onto ASSP. It can be observed (Fig. 8 and 9) that the adsorption capacities of MV dyes increased from $2.27 \mathrm{mg} / \mathrm{g}$ to $11.39 \mathrm{mg} / \mathrm{g}$ respectively. While the percentage removal of MV decreased from 95.3 to $77.77 \%$ as initial concentration increased from 25 to $125 \mathrm{mg} / \mathrm{L}$. The increase in adsorption capacity with increase in initial concentration is due to the high driving force which overcomes the mass transfer resistance between the solid/aqueous phase leading to more adsorption [15]. The decrease in percentage removal with increase in dye concentration is due to the fact that, for a given mass of adsorbent, the amount of dye it can adsorb is fixed. Thus, the higher the concentration of the dye the smaller the percentage it can remove [16]. 


\section{5: Effect of Temperature}

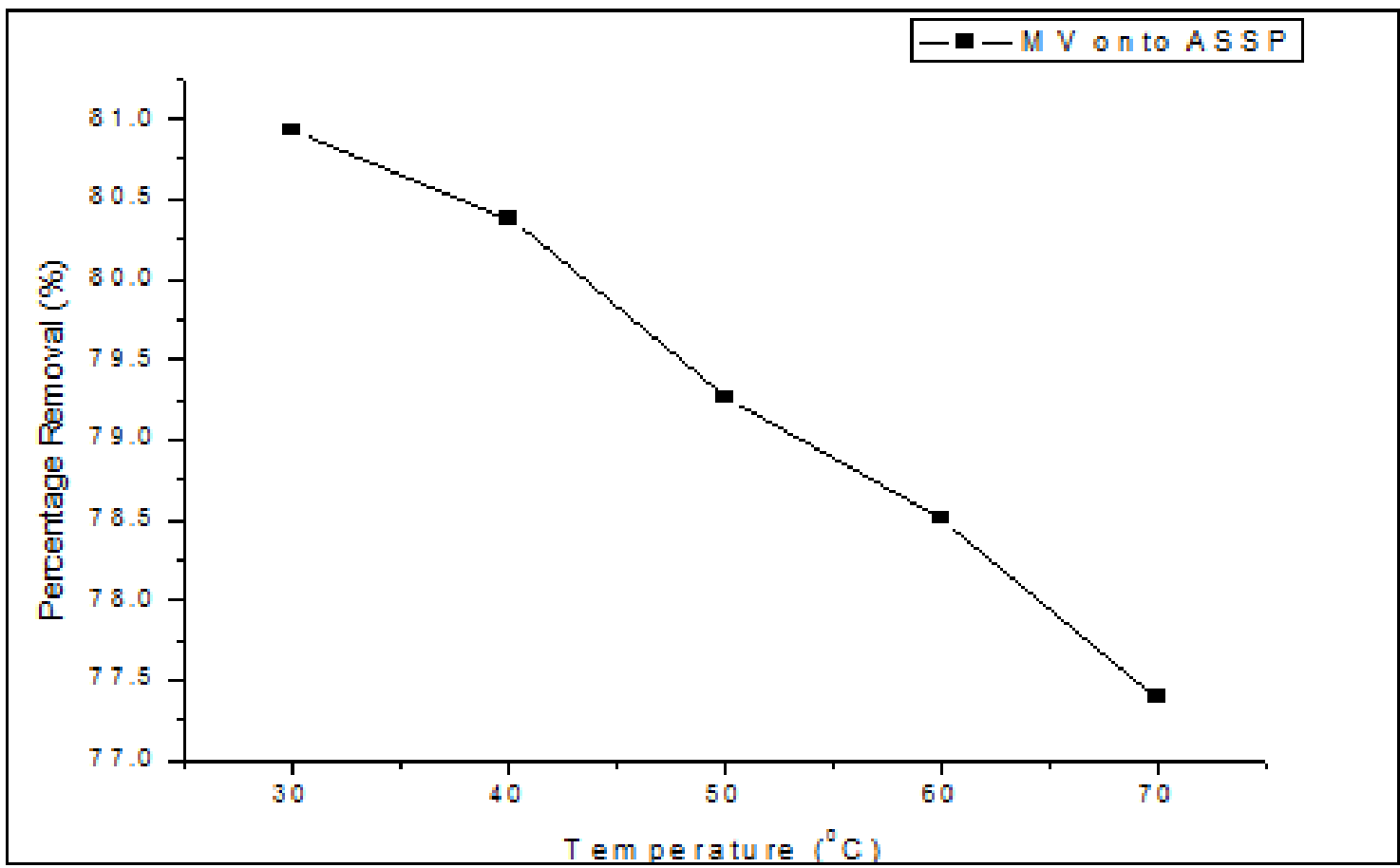

Fig.10: Effect of temperature for the percentage removal of MV onto ASSP

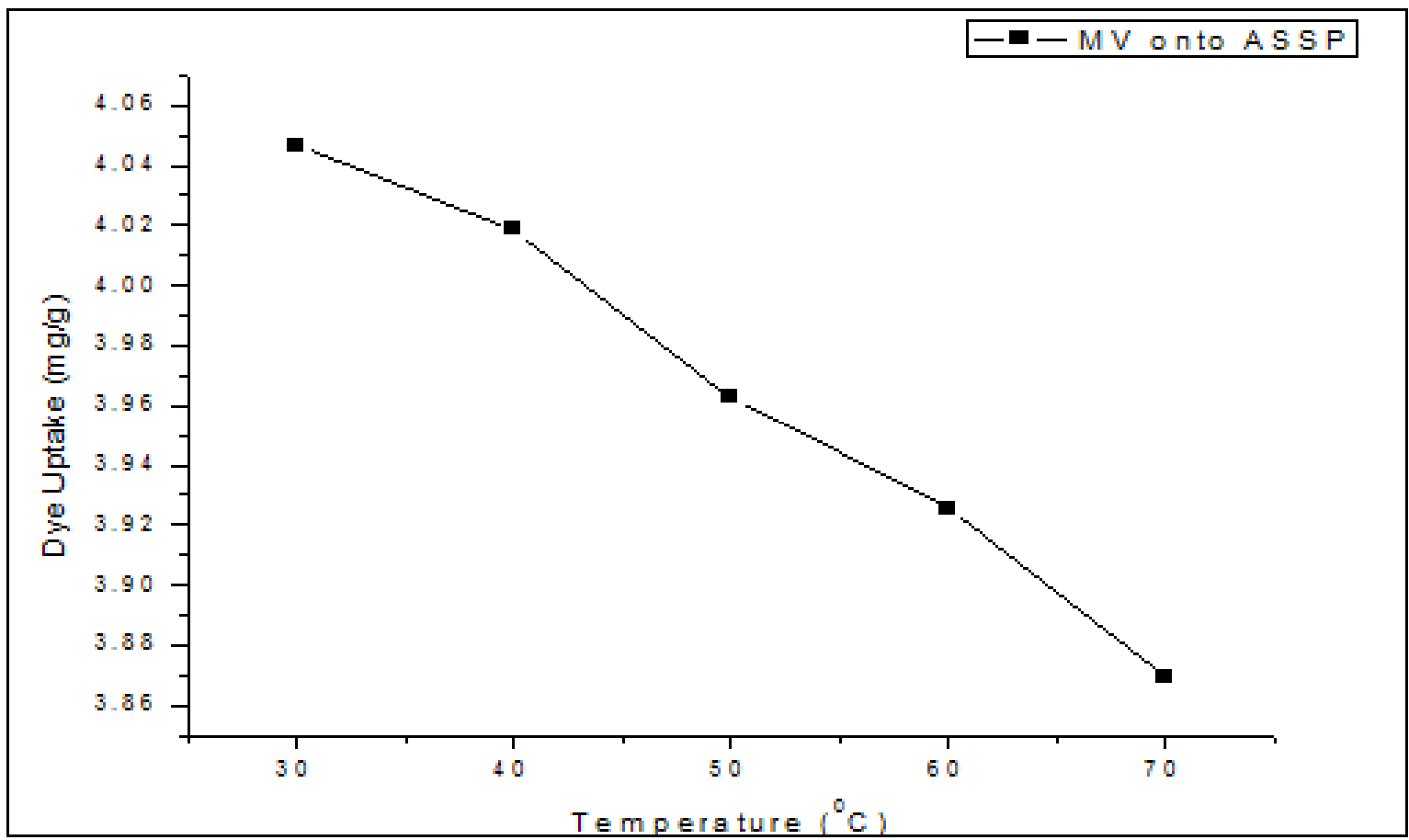

Fig.11: Effect of temperature for the adsorption capacity of MV onto ASSP

Fig.10 and 11 show the effect of percentage removal and adsorption capacity of MV onto ASSP. The percentage removal and adsorption capacity decreased from $80.9 \%$ to $77.40 \%$ and $4.05 \mathrm{mg} / \mathrm{g}$ to $3.87 \mathrm{mg} / \mathrm{g}$ for MV onto ASSP, as temperature increased from 30 to $70{ }^{\circ} \mathrm{C}$. The decrease in adsorption capacity and efficiency for the adsorption of MV onto ASSP with increase in temperature can be attributed mainly to the fact that as the temperature increases, the physical bonding between the dye (adsorbate) and the active sites of the adsorbent weakened. In addition, the dye solubility also increased which caused the interaction between the solute and solvent to become stronger than that between solute and adsorbent. Therefore, the solute became more difficult to adsorb [17]. 


\subsection{Effect of $\mathrm{pH}$}

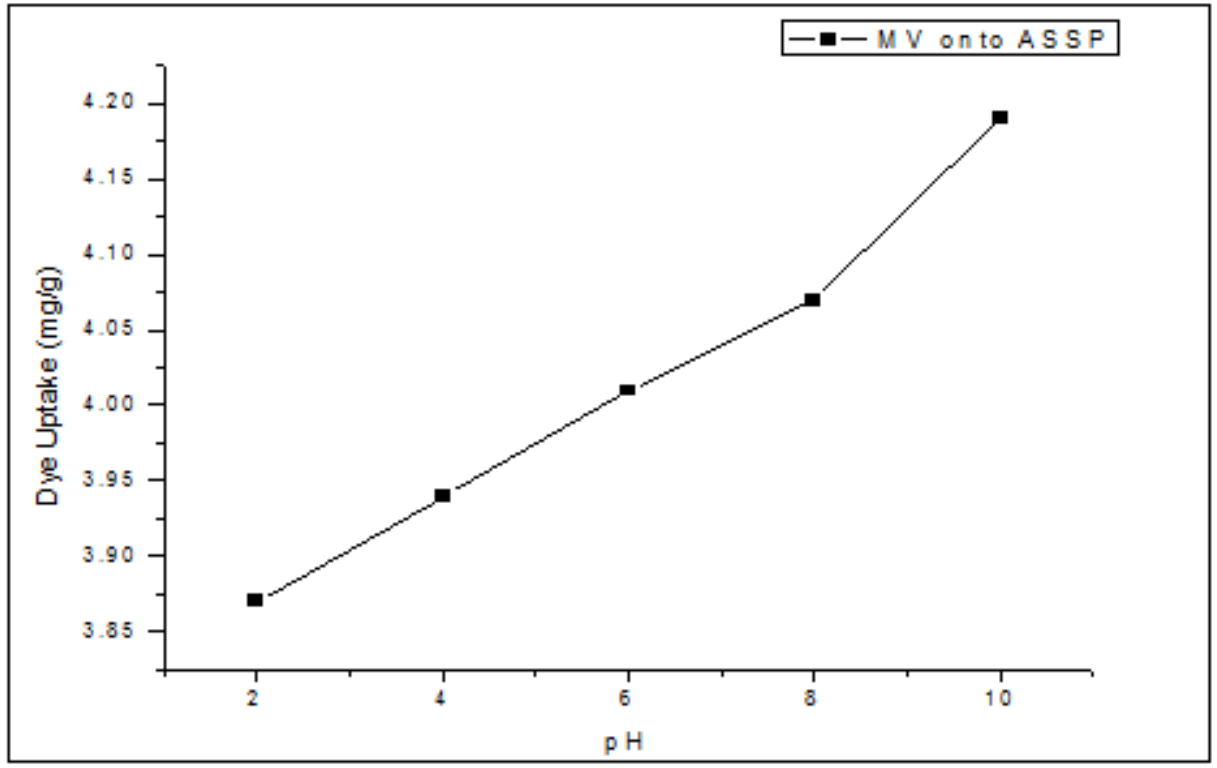

Fig.12: Effect of $\mathrm{pH}$ on the adsorption capacity of MV onto ASSP

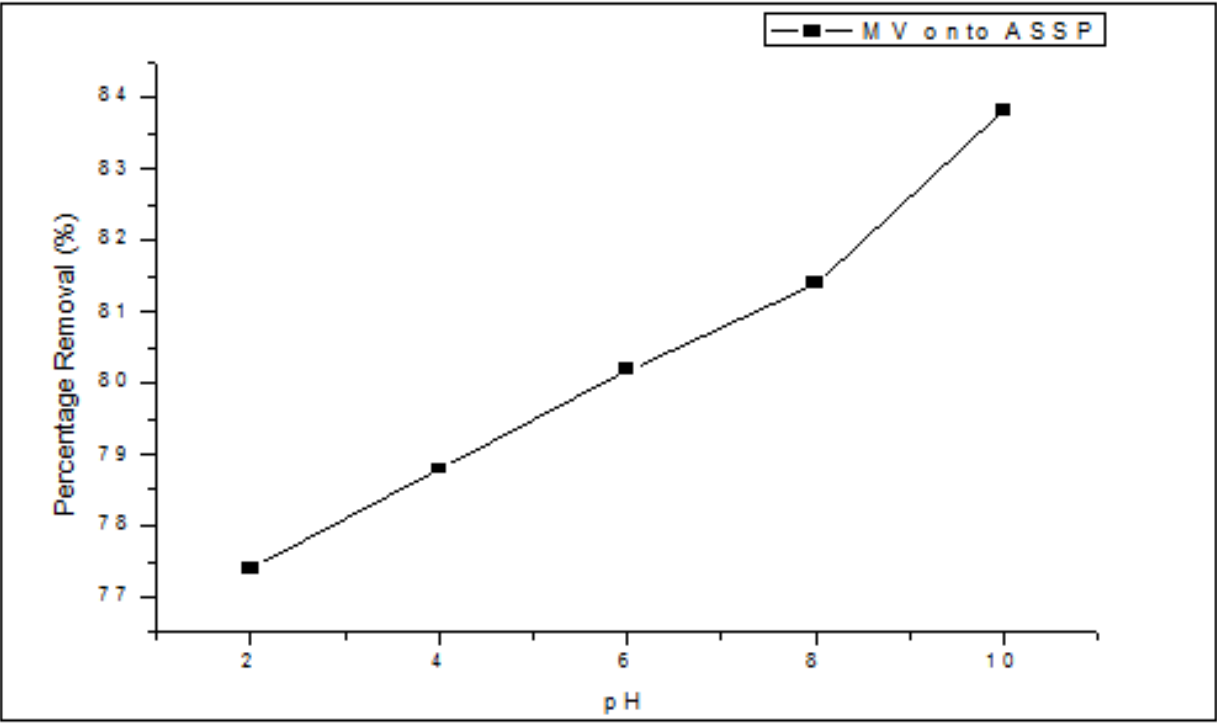

Fig.13: Effect of $\mathrm{pH}$ on the percentage removal of MV onto ASSP

It can be observed from Fig. 12 and 13 that the adsorption capacity and percentage removal of MV dye by ASSP increased from $3.87 \mathrm{mg} / \mathrm{g}$ to $4.19 \mathrm{mg} / \mathrm{g}$ and from 77.40 to $83.81 \%$ respectively with increase in $\mathrm{pH}$ from 2 to 10 . Optimum sorption was obtained at $\mathrm{pH}$ of 10 . The increase in percentage removal and adsorption capacity with increase in $\mathrm{pH}$ can be attributed to the fact that at low $\mathrm{pH}$ values of the solution, the presence of excess hydrogen ion in the solution competes with the cationic groups of the MV dye for the adsorption sites on the adsorbent surface. While at high $\mathrm{pH}$ values, the positive charges $\left(\mathrm{H}^{+}\right)$at the solution interphase decreases and the adsorbent surface is more negatively charged, thus enhancing attraction of more amounts of the cations of the MV dye [18].

\subsection{Adsorption Isotherms}

Two isotherm models have been tested in the present research, namely, Langmuir and Freundlich models.

The linear form of Langmuir equation is given as

$\frac{C_{e}}{q_{e}}=\frac{1}{q_{m} K_{l}}+\frac{C_{e}}{q_{m}}$ 
Where $q_{e}(\mathrm{mg} / \mathrm{g})$ is the amount of dye adsorbed at equilibrium, $q_{m}(\mathrm{mg} / \mathrm{g})$, the amount of dye adsorbed when saturation is attained,

$C_{e}$ is the equilibrium dye concentration $(\mathrm{mg} / \mathrm{l})$ and $K_{l}$ is Langmuir constant related to the binding strength of dye onto the adsorbent.

The linearized form of Freundlich equation is expressed as

$\log q_{e}=\log K_{f}+\frac{1}{n} \log C_{e}$

Where $K_{f}$ and $n$ are the Freundlich constants that represent adsorption capacity and intensity (strength) of adsorption respectively.

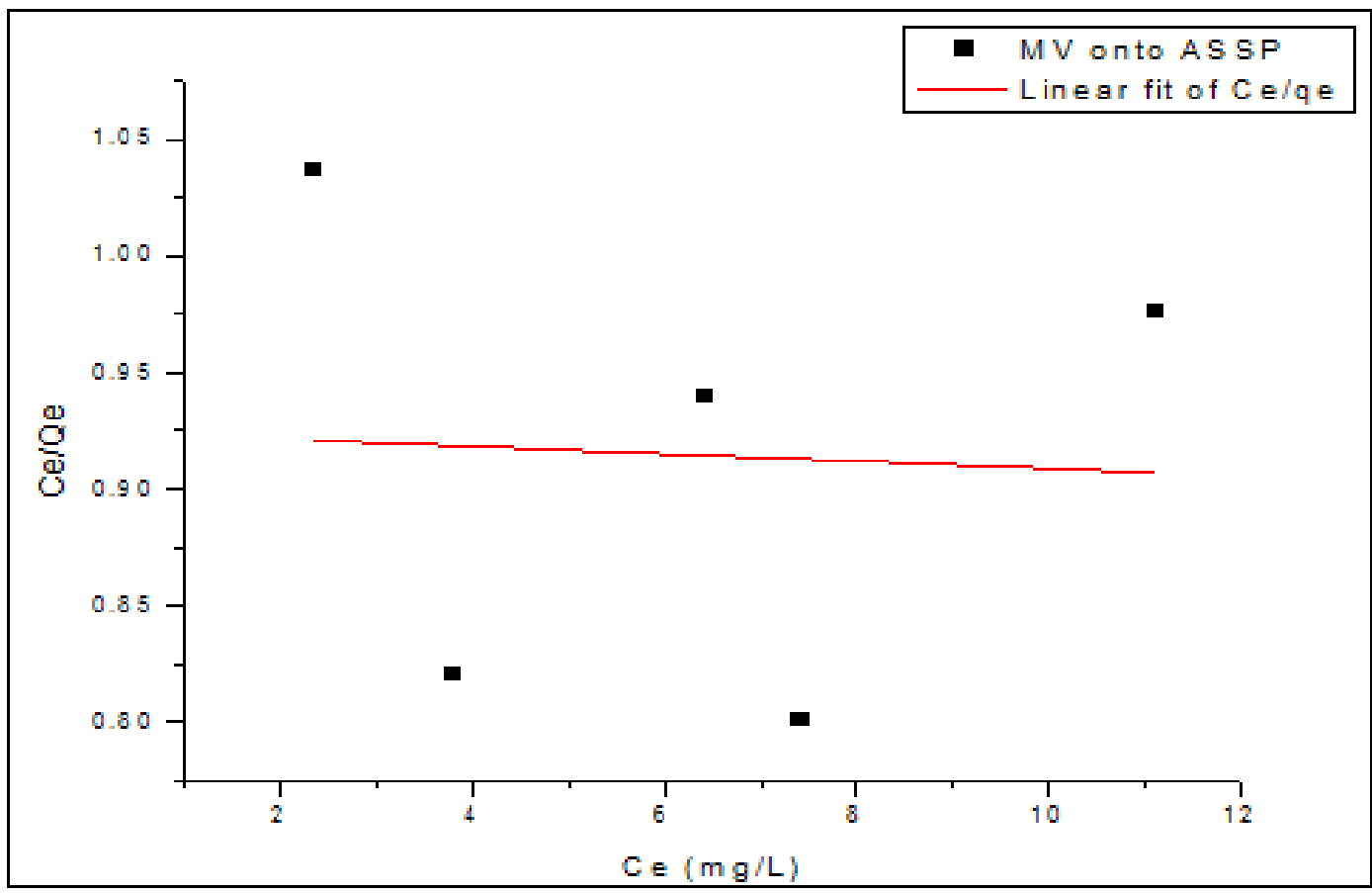

Fig.14: Langmuir isotherm plot for the adsorption of MV onto ASSP

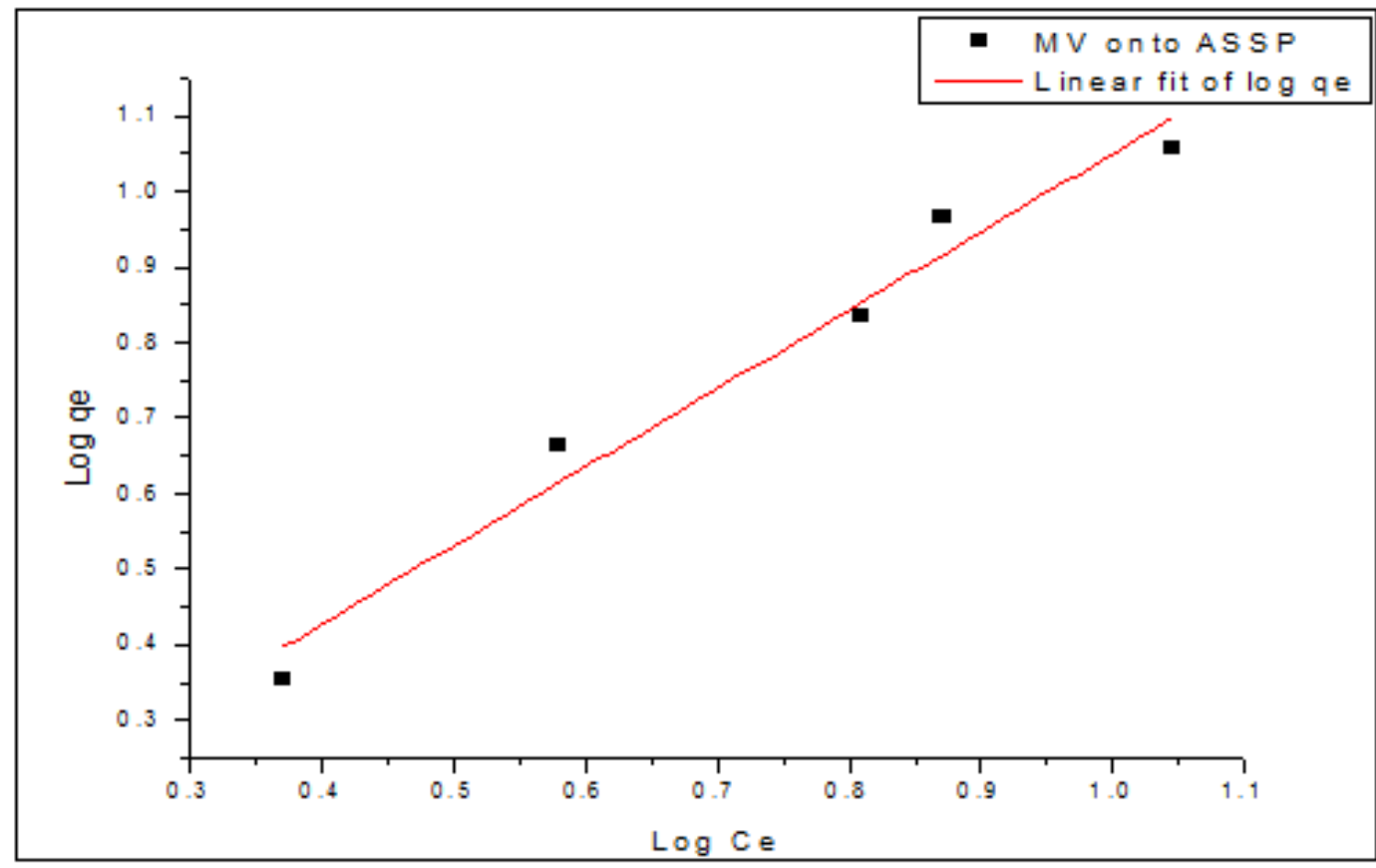

Fig.15: Freundlich isotherm plot for the adsorption of MV onto ASSP 
Fig 14 and 15 show the Langmuir and freundlich model plot for the adsorption of MV onto ASSP respectively. The isotherm parameter and $\mathrm{R}^{2}$ values are summarized in Table 1 . It is evident from the plots and the values of correlation coefficient $\mathrm{R}^{2}$ (Table 1), that the Langmuir isotherm plot was inadequate in describing the adsorption processes. The experimental data fitted well with the Freundlich isotherm model, hence, the Freundlich model is efficient in describing the adsorption of MV onto ASSP and such adsorptions mainly occurred on the heterogeneous surface of the ASSP powder.

Table 1: Isotherm Parameters and values of correlation coefficient for MV adsorption onto ASSP

\begin{tabular}{|l|l|l|l|l|l|}
\hline Langmuir & & & & & Freundlich \\
\hline $\mathbf{q}_{\operatorname{max~mg/g}}$ & $\mathbf{K}_{\mathbf{L}}$ & $\mathbf{R}^{\mathbf{2}}$ & $\mathbf{n}$ & $\mathbf{K}_{\mathbf{f ~ m g} / \mathbf{g})(\mathbf{L} / \mathbf{m g})} \mathbf{1 / n}$ & $\mathbf{R}^{\mathbf{2}}$ \\
\hline & & & & & \\
\hline
\end{tabular}

\subsection{Adsorption Kinetics}

The pseudo-first-order, pseudo-second-order kinetic models were applied to study the adsorption kinetics and to compute the extent of uptake in the adsorption process.

3.8.1: Pseudo-first-order Kinetic Model

The linear form of the pseudo-first-order kinetic mode is represented by

$\ln \left(\mathbf{q}_{\mathrm{e}}-\mathbf{q}_{\mathrm{t}}\right)=\ln \mathbf{q}_{\mathrm{e}}-\mathrm{K}_{1} \mathbf{t}$

were $\mathrm{q}_{\mathrm{e}}$ and $\mathrm{q}_{\mathrm{t}}$ are the values of amount of the dye adsorbed per unit mass on the adsorbent at equilibrium and at various time $t$, respectively, $\mathrm{K}_{1}$ is the Pseudo-first-order adsorption rate constant $\left(\mathrm{min}^{-1}\right)$. The values of $\mathrm{K}_{1}$ and calculated $\mathrm{q}_{\mathrm{e}}$ can be determined from the slope and intercept respectively, of the linear plot of $\ln \left(\mathrm{q}_{\mathrm{e}}-\mathrm{q}_{\mathrm{t}}\right)$ versus t.

3.8.2: Pseudo-second-order Kinetic Model

The pseudo-second-order kinetic model is expressed by

$\frac{t}{q_{t}}=\frac{1}{k_{2} q_{e}^{2}}+\frac{1}{q_{e}} t$

Where $\mathrm{K}_{2}$ is the pseudo-second-order adsorption rate constant $(\mathrm{g} / \mathrm{mg} / \mathrm{min})$ and $\mathrm{q}_{\mathrm{e}}$ is the amount of dye adsorbed $(\mathrm{mg} / \mathrm{g})$ on the adsorbent at equilibrium. The initial adsorption rate, $\mathrm{h}\left(\mathrm{mg} \cdot \mathrm{g}^{-1} \cdot \mathrm{min}^{-1}\right)$ is expressed as:

$\mathrm{h}=\mathbf{k}_{\mathbf{2}} \mathbf{q}_{\mathbf{e}}^{2}$

The plot of $\mathrm{t} / \mathrm{q}_{\mathrm{t}}$ versus gives a linear relationship which allow computation of $\mathrm{k}_{2}$, $\mathrm{h}$ and calculated $\mathrm{q}_{\mathrm{e}}$. Among these models, the criterion for their applicability is based on judgment on the respective correlation coefficient $\left(\mathrm{R}^{2}\right)$ and agreement between experimental and calculated value of $\mathrm{q}_{\mathrm{e}}$

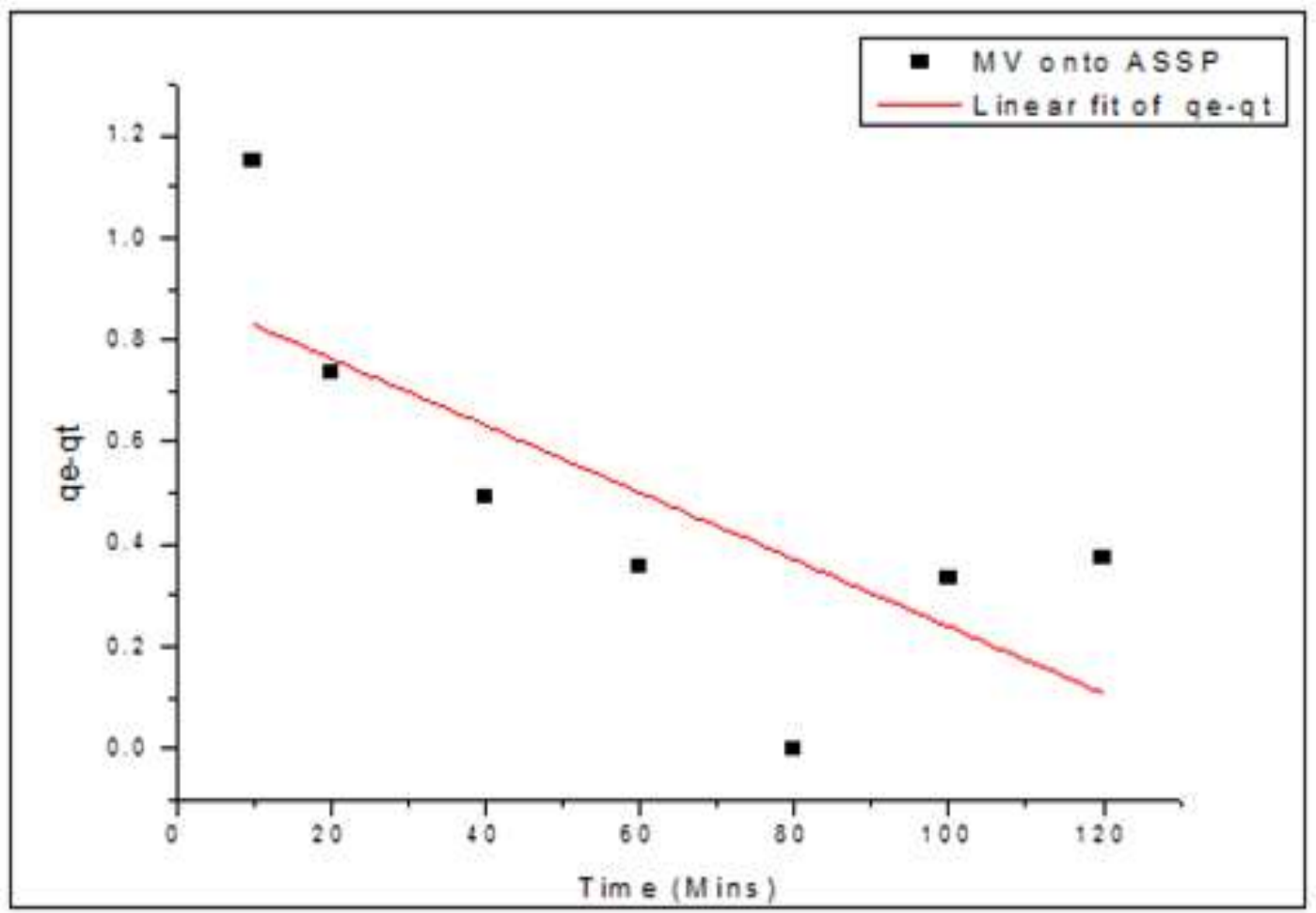

Fig.16: Pseudo first order plot for the adsorption of MV onto ASSP 


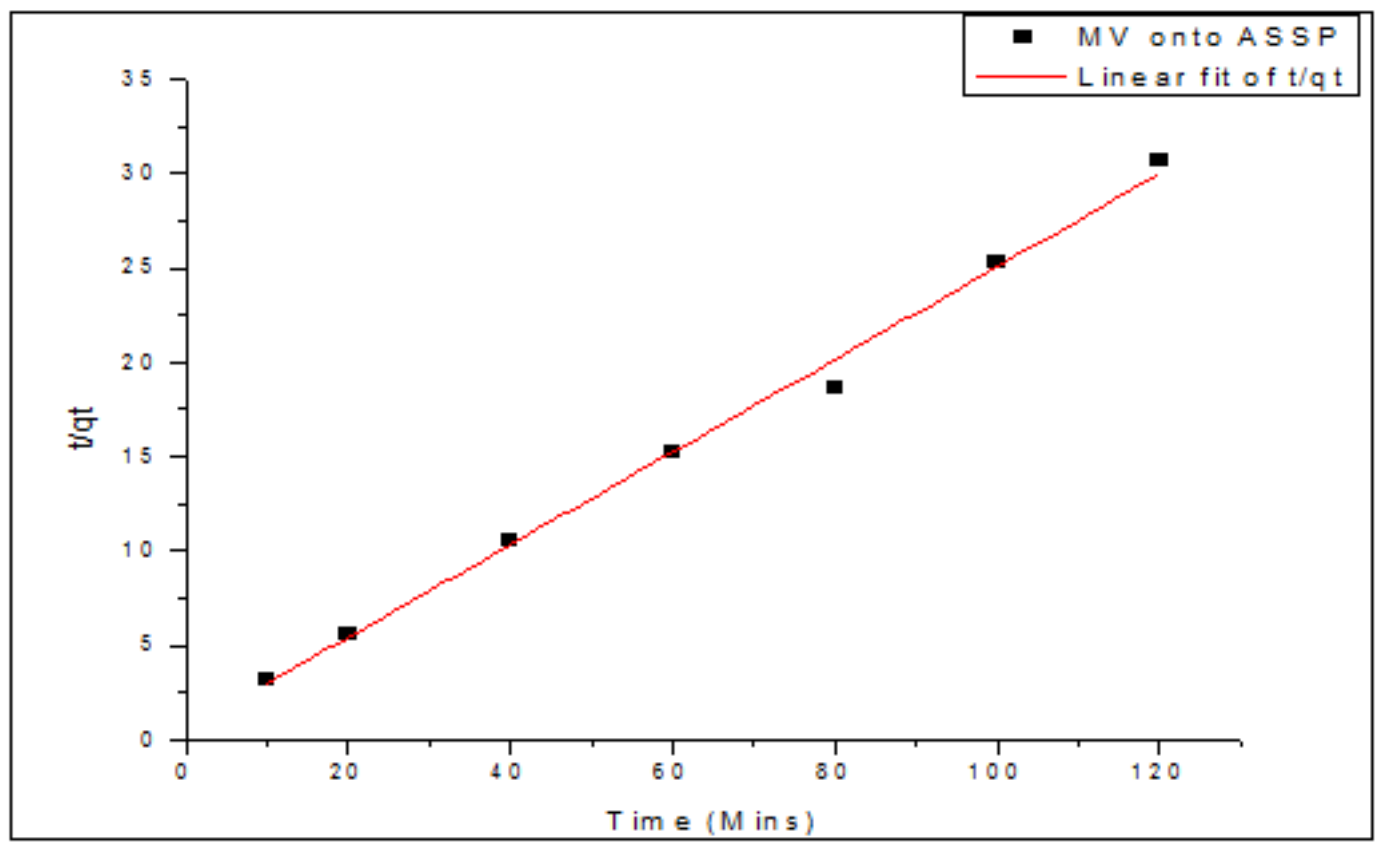

Fig. 17: Pseudo second order plot for the adsorption of MV ASSP

Fig.16\&17 show the pseudo-first-order and second order kinetics for the adsorption of MV by ASSP. The pseudo-first-order rate constant $\left(\mathrm{k}_{1}\right)$ and $\mathrm{q}_{\mathrm{e}}$ determined from the model are presented in Table 2 . It is observed from Fig. 16 that the relationship between the dye solution diffusivity, $\ln \left(\mathrm{q}_{\mathrm{e}}-\mathrm{q}_{\mathrm{t}}\right)$ against $\mathrm{t}$ is nonlinear. It is also observed that the calculated $\mathrm{q}_{\mathrm{e}}$ values did not agree with the experimental $\mathrm{q}_{\mathrm{e}}$ since the calculated $\mathrm{q}_{\mathrm{e}}$ values were neither equal nor reasonably close to the experimental $\mathrm{q}_{\mathrm{e}}$ values (Table 2). Therefore, pseudofirst-order model was inadequate in representing the adsorption of MV onto ASSP.

Fig. 17 depicts the pseudo-second-order kinetics for the adsorption of MV dye onto ASSP. The pseudosecond-order rate constant $\mathrm{k}_{2}$, and $\mathrm{q}_{\mathrm{e}}$ determined from the model are presented in Table 2 . It can be observed from Table 2 that there is good agreement between the calculated $\mathrm{q}_{\mathrm{e}}$ value and the experimental $\mathrm{q}_{\mathrm{e}}$ value i.e. $\mathrm{q}_{\mathrm{e}}$ (cal.) and $\mathrm{q}_{\mathrm{e}}$ (exp.) for the adsorption of MV by ASSP. In addition, highly linear plots with high values of correlation coefficient were also observed from Fig.17 for the adsorption of MV dye by ASSP. It is therefore evident that Pseudo-second-order is the best fit kinetic model in describing the adsorption process and is therefore very adequate in describing and representing the kinetics of the adsorptions.

Table 2: Pseudo-first and second order kinetic model parameters for MV adsorption onto ASSP

\begin{tabular}{|c|c|c|c|c|c|c|c|}
\hline \multicolumn{3}{|c|}{ Pseudo-First Order Model } & \multicolumn{5}{|c|}{ Pseudo-Second Order Model } \\
\hline $\begin{array}{l}q_{\mathrm{e}}(\exp ) \\
(\mathrm{mg} / \mathrm{g})\end{array}$ & $\mathrm{k}_{1}\left(\mathrm{~g} \cdot \mathrm{mg}^{-1} \mathrm{~min}^{-1}\right)$ & $\begin{array}{l}q_{\mathrm{e}}(\mathrm{cal}) \\
(\mathrm{mg} / \mathrm{g})\end{array}$ & $\mathbf{R}^{2}$ & $\begin{array}{c}\text { h } \\
\left(\mathrm{mg}^{-1} \mathrm{~g}^{-1} \mathrm{~min}^{-1}\right)\end{array}$ & 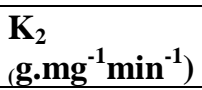 & $\begin{array}{l}q_{\mathrm{e}}(\mathrm{cal}) \\
(\mathrm{mg} / \mathrm{g})\end{array}$ & $\mathbf{R}^{2}$ \\
\hline 4.289 & 0.021 & 0.731 & 0.06 & 1.840 & 0.111 & 4.08 & 0.994 \\
\hline
\end{tabular}

\section{9: Adsorption Thermodynamics}

The thermodynamic parameters such as change in Gibb's free energy $\left(\Delta \mathrm{G}^{0}\right)$, change in enthalpy $\left(\Delta \mathrm{H}^{0}\right)$ and change in entropy $\left(\Delta S^{0}\right)$ for the adsorption of MV onto ASSP have been determined using the following equations:

The Gibb's free energy, $\Delta \mathrm{G}$, equation is expressed as follows:

$\Delta \mathbf{G}=-\mathbf{R T} \ln K_{\text {ads }}$

The equilibrium constants ( $\mathrm{Kads}$ ) were calculated according to the following equation:

$$
K_{\text {ads }}=\frac{\text { Dye concentration on the solid (adsorbent) at equilibrium }\left(\mathbf{q}_{\mathbf{e}}^{\mathbf{m}}\right)}{\text { Dye concentration in solution at equilibrium }\left(C_{e}\right)}
$$

The Van't Hoff equation is expressed as follows:

$\ln K_{\mathrm{ads}}=\frac{\Delta \mathbf{S}^{\mathbf{0}}}{\mathbf{R}}-\frac{\Delta \mathbf{H}^{\mathbf{0}}}{\mathbf{R T}}$

Where $R$ is gas constant, $T$ is absolute temperature in Kelvin, $\Delta S^{0}$ and $\Delta H^{0}$ are entropy and enthalpy respectively. The plot of $\ln K_{a d s}$ versus $1 / T$ gives a linear relationship, which allows the computation of $\Delta H$ and $\Delta S$ values from the slope and intercept respectively. 


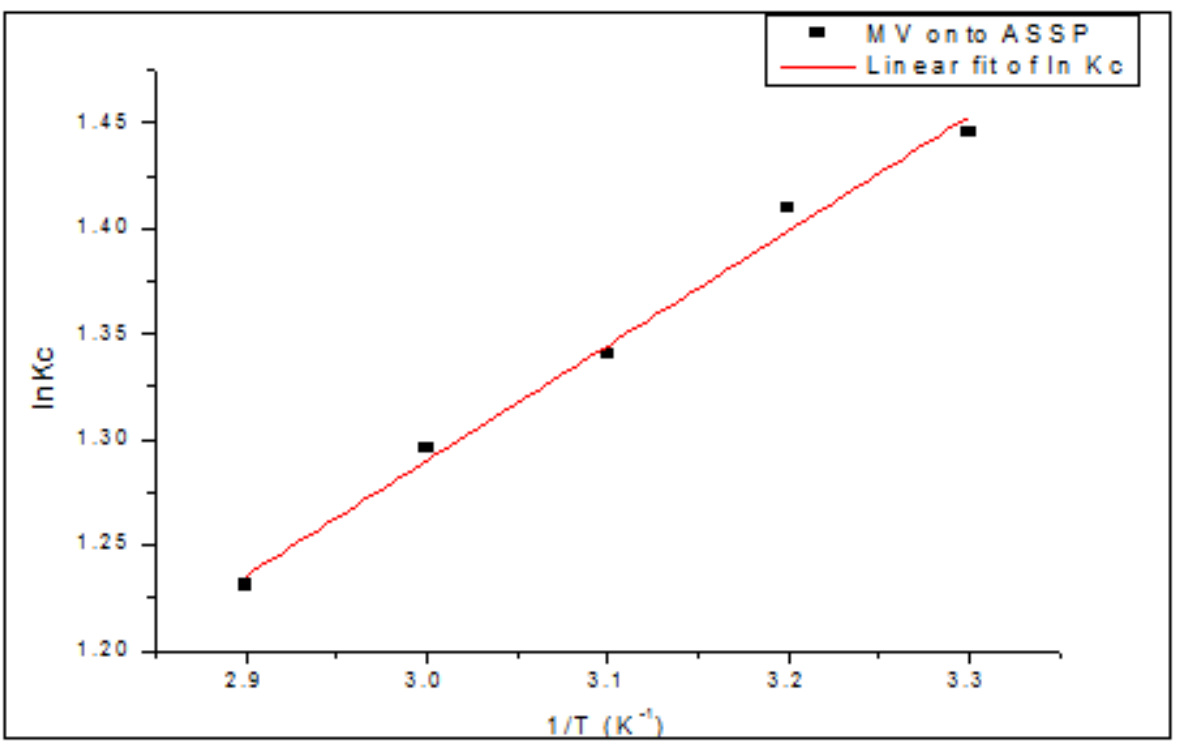

Fig.18: Van't Hoff plot for the adsorption of MV onto ASSP

Fig.18 shows the linear Van't Hoff equation plots for the adsorption of MV dye on ASSP.

Negative $\Delta G^{0}$ values obtained at all temperatures (Table 3) indicate the feasibility and the spontaneous nature of MV dye adsorption onto ASSP.

The negative $\Delta H^{0}$ value confirms the exothermic nature of the adsorption of MV onto ASSP. The positive value of $\Delta S^{0}$ obtained for the adsorption of MV indicates the increase in randomness at the solid/solution interfaces during the adsorption [19].

Table 3: Thermodynamic data and parameter for MV adsorption

\begin{tabular}{|c|c|c|c|}
\hline $\mathbf{T}(\mathrm{K})$ & $\Delta \mathrm{G}(\mathrm{KJ} / \mathrm{mol} . \mathrm{K}$ & $\Delta \mathrm{H}(\mathrm{KJ} / \mathrm{mol} . \mathrm{K})$ & $\Delta \mathrm{S}(\mathrm{KJ} / \mathrm{mol})$. \\
\hline 303 & -3641.38 & \multirow[t]{5}{*}{-4.518} & \multirow[t]{5}{*}{2.828} \\
\hline 313 & -3668.48 & & \\
\hline 323 & -3599.58 & & \\
\hline 333 & -3587.32 & & \\
\hline 343 & -3509.79 & & \\
\hline
\end{tabular}

\section{Conclusion}

The potential of almond seed shell (ASS) powder as an effective adsorbent for the removal of MV dye from aqueous medium has been identified. The adsorption of MV onto ASSP was found to be influenced by contact time, adsorbent dose, initial MV concentration, temperature and initial $\mathrm{pH}$ of the solution. The optimum adsorption of MV dye was found at $\mathrm{pH} 10$. Temperature had strong influence on the adsorption process and the maximum removal was observed at lower temperature. The equilibrium was attained at $80 \mathrm{~min}$, after which there was no increase in MV adsorption. The kinetic studies revealed that the adsorption process followed the pseudo-second-order kinetic model. The study on equilibrium sorption revealed that Freundlich isotherm model was the best fit. The calculated thermodynamic parameters indicated a spontaneous and exothermic nature of the adsorption of MV dye onto ASS powder. The present study showed that almond seed shell powder can be effectively used as an inexpensive and efficient adsorbent without any modification for the treatment of dye effluents or waste water.

\section{Reference}

[1]. C. Allegre, P. Mouline, M. Maisseu, F. Charbit, Treatment and reuse of reactive dyeing effluents, J. Memb. Science, 269, 2006, 1517.

[2]. C. Umpuch, B. Jutarat, Adsorption of organic dyes from aqueous solution by surfactant modified corn straw, Inter. J. Chem. Eng. Applications, 4(3), 2013, $134-139$.

[3]. T. Robinson, G. McMullan, R. Marchant, P. Nigam, Remediation of dyes in textile effluent: a critical review on current treatment technologies with a propose alternative, J. Biores Tech. 77, 2001, 247-275.

[4]. A. Hashem, R. A. Akasha, A. Ghith, D.A. Hussein, Adsorbent based on agricultural wastes for heavy metal and dye removal: A review, Energy Educ. Sci. Technol. 19, 2007, 69-86.

[5]. S. Chowdhury, R. Mishra, P. Saha, Adsorption thermodynamics, kinetics and isosteric heat of adsorption of malachite green onto chemically modified rice husk, J. Desal. 2010, 07-047.

[6]. A .Ezgi, B. Miifit, Y. Mustapa, Removal efficiency of a calyx [4] arene-based polymer for water-soluble carcinogenic direct azo dyes and aromatic amines, Journal of Hazardous Materials, 162, 2008, 960-966. 
[7]. A.K. Asiagwu, H. I Owamah, V.O. Illoh, Kinetic and thermodynamic models for the removal of amino-phenol (dye) from aqueous solutions using groundnut (arachis hypogea) shells as the biomass, Advances in Applied Science Research, 3(4), 2012,2257 - 2265.

[8]. W. Sumanjit, T.P.S. Walia, and K. Ravneet, Removal of health hazards causing acidic dyes from aqueous solution by the process of adsorption, Online Journal of Health and Allied sciences, 6 (3), 2007, 1-10.

[9]. S.P. Kumar, M. Palaniyappan, M. Priyadharshini, A.M. Vigensh, A. Thonjiappan, P.A F. Sebastina, R.A. Tanvir and R. Srinath, Adsorption of basic dye onto raw and surface-modified agricultural waste, Env. Progress and Sustainable Energy, 33(1), 2013, 87 98.

[10]. M.L. Gary, L.P. Donald, S.K. George, and R.V. James, Spectroscopy (Bellingham, Washington: Brooks/Cole 2010).

[11]. N. Sharma, and B.K. Nnadi, Utilization of sugarcane baggase, an agricultural waste to remove malachite green dye from aqueous solution. J. Mater. Environ. Sci., 4(6), 2013, 1052-1065.

[12]. J.A. Kagbu, J.O. Amupitan, J.O. Oyedeji and P. Elaigwu, Evaluation of yankassa sheep wool as an adsorptive matrix for bleaching textile effluents, J. Chem. Soc. Nigeria, 26(1), 2001, 14-17.

[13]. M.K Purkait, A.S. Maiti, D. Gupta, Removal of congo red using activated carbon and its regeneration, J. Hazard. Mater. 145 (1-2), 2007, 287-295.

[14]. . Taher, Use of $\mathrm{CaCl}_{2}$ modified bentonite for removal of congo red dye from aqueous solutions, Desalination, $249,2009,797-801$.

[15]. T.C.R. Bertolini, J.C. Izidoro, P.M. Carina, A.F. Denise, Adsorption of crystal violet dye from aqueous solution onto zeolites from coal fly and bottom ashes, Electronic Journal of Chemistry, 5(3), 2013, 179-191.

[16]. A.M. Saeed, M. Sharif, Iqbal, .Application potential of grapefruit peel as dye sorbent: Kinetics, equilibrium and mechanism of crystal violet adsorption, J. Hazard. Mater. 179, 2010, 564-572.

[17]. P. Jayaraj, S. J. Thanaraj, T. Natarajan and P. M.D. Prasath, , Removal of Congo red Dye from aqueous solution using acid activated ecofriendly low cost carbon prepared from marine algae valoria bryopsis, J. Chem. Pharm. Res., 3(3), $2011,389-396$.

[18]. A. Kant, Removal of congo red from an aqueous solution by fungus aspergillusniger, Adv. Environ. Res., 7, $2002,239-247$.

[19]. J.R. Baseri, P.N. Palanisamy and P.S. Kuma, Adsorption of basic dyes from synthetic textile effluent by activated carbon prepared from thevetia peruviana, Indian J. Chem. Technol., 19, 2012, 311-312. 